\title{
Transdermal microneedle-mediated delivery of polymeric lamivudine-loaded nanoparticles
}

\author{
E. Ramadan, Th. Borg, G. M. Abdelghani and Noha Mohammed Saleh*
}

*Correspondence: nunu_ramy@yahoo.com

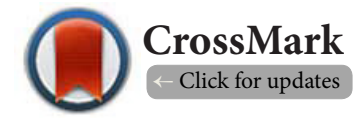

Department of Pharmaceutics, Faculty of Pharmacy, Mansoura University, Mansoura 35516, Egypt.

\begin{abstract}
Background: The goal of this study was to develop a novel drug delivery system (NDDS) of lamivudine (LAM) to overcome some drawbacks associated with LAM short half-life. To fulfill this goal, polymeric LAM-loaded nanoparticles were prepared and their transdermal deliveries via passive and microneedles (MNs)-mediated transport were investigated.

Methods: First, nanoparticles were prepared by double emulsion-solvent evaporation method using polylactic-co-glycolic acid (PLGA) and bovine serum albumin (BSA) as a polymer and a stabilizer respectively. Two different concentrations of $\operatorname{LAM}(10$ and $20 \mathrm{mg} / \mathrm{ml})$ were used for preparing LAM-loaded nanoparticles $\left(\mathrm{NP}_{10}\right.$ and $\mathrm{NP}_{20}$ respectively). After that, the prepared nanoparticles were characterized with regard to their particle size (PZ), polydispersity index (PDI), zeta potential (ZP), percent yield (\% rield), morphology, drug loading capacity (\%LC), and entrapment efficiency (\%EE). Then, in vitro release of LAM from the LAM-loaded nanoparticles was studied and physical stability of the optimized LAM-loaded nanoparticles $\left(\mathrm{NP}_{20}\right)$ was examined. Finally, permeation of $\mathrm{NP}_{20}$ and LAM solution across plain and MNs-treated excised rabbit skin was investigated.

$\underline{\text { Results: }}$ The particle size of the prepared nanoparticles ranged from $152.87 \pm 1.27 \mathrm{~nm}$ to $196.67 \pm 1.74 \mathrm{~nm}$, the PDI ranged from $0.089 \pm 0.01$ to $0.145 \pm 0.03$ and the $\mathrm{ZP}$ range was from $-42.2 \pm 7.35 \mathrm{mV}$ to $-47.5 \pm 6.55$ $\mathrm{mV}$. All nanoparticles have distinct spherical shapes with smooth surface and thick shells of the BSA. The entrapment efficiencies of the LAM-loaded nanoparticles were $23.01 \pm 4.75 \%$ and $26.31 \pm 2.8 \%$. A biphasic pattern of drug release was observed in the in vitro release studies with initially faster release profile followed by prolonged release for extended time. The physical stability assessment of $\mathrm{NP}_{20}$ suspension showed that no significant variation of $\mathrm{PZ}, \mathrm{PDI}$ and $\mathrm{ZP}$ could be detected during the storage period of six months. The steady state flux values of the LAM-loaded $\mathrm{NP}_{20}$ across untreated skin and the MNs-treated skin were $7.49 \pm 1.46 \mu \mathrm{g} . \mathrm{cm}^{-2} \cdot \mathrm{hr}^{-1}$ and $15.77 \pm 1.5 \mu \mathrm{g} . \mathrm{cm}^{-2} \cdot \mathrm{hr}^{-1}$ respectively. Also, the permeation study showed the possibility of transdermal delivery of the LAM-loaded nanoparticles. In the same time, this delivery could be enhanced significantly by MNs-pretreatment of skin. The steady state flux of the LAM-loaded $\mathrm{NP}_{20}$ across the MNs-treated skin was significantly greater than that of passive transport across untreated skin.
\end{abstract}

Conclusions: Polymeric LAM-loaded nanoparticles could serve as a potential NDDS for the sustained transdermal delivery. The steady state flux could be enhanced by more than two folds using the MNsmediated transport.

Keywords: Novel, PLGA, particle size, zeta potential, transdermal, lamivudine, nanoparticles, microneedle

\section{Background}

LAM is a commonly used hydrophilic antiretroviral drug for treating AIDS and hepatitis B. As LAM is phosphorylated to its active metabolites, it can inhibit the viral reverse transcriptase enzyme competitively and act as a chain terminator of viral DNA synthesis [1]. LAM is conservatively assigned to BCS class III according to its solubility and the permeability classification [2]. LAM has short biological half-life that ranges from 4 to 6 hours 
Ramadan et al. Journal of Pharmaceutical Technology \& Drug Research 2016,

http://www.hoajonline.com/journals/pdf/2050-120X-5-1.pdf

doi: 10.7243/2050-120X-5-1

and it requires multiple and frequent oral administration for a prolonged period of time (lifelong treatment of AIDS and for one year in case of hepatitis patients) [3].

Transdermal route, which results in less frequent dosing regimens, could be considered as a better alternative to reach constant plasma levels for prolonged periods of time. Limited studies attempted the transdermal delivery of LAM using liposomes [4], ethosomes [3] and microemulsion [5]. The poor stability, high cost and complex technique limit the use of nanovesicular systems on a large scale. On the other hand, microemulsion application may be non-appropriate for long term treatment that could extend for more than one year. Therefore, a novel approach involving LAM-loaded nanoparticles and MNs insertion was used as a NDDS to enhance transdermal delivery of small molecular weight drugs across the skin layers [6].

Nanoparticles (NPs) applications are unconventional and non-invasive techniques approved for improving skin permeation of various drugs. These techniques can be used to improve the treatment strategy, formulation and delivery of antiviral drugs $[7,8]$. Transdermal utilization of NPs allows reduction of dose, extended or enhanced release into skin and protection from enzymatic degradation. There is an emerging agreement that the NPs cannot usually penetrate Stratum cormeum (SC), although they may well deposit in hair follicles. Hence, hair follicles can be used as a reservoir for drug delivery to localize the drug to the hair follicles or to deliver the drug to the surrounding viable epidermal cells $[9,10]$.

A drug can be entrapped or encapsulated within the nanoparticle (NP), physically adsorbed on or chemically linked to the surface of NP. Various biocompatible and biodegradable synthetic or semi-synthetic polymers. They comprise poly $(\varepsilon-$ caprolactone) [11], chitosan [12], polylactic acid (PLA) [13] and polylactic co-glycolic acid (PLGA) [14] have shown potential in transdermal drug delivery. Drug release from PLGA and PLA NPs and subsequent biodegradation are important for developing successful formulations [15]. Hence, PLGA was selected as a polymer for preparation of the polymeric NPs.

Microneedles array technology has involved growing interest as a mean of enhancing transdermal delivery of many drugs in a less invasive manner [16]. The MNs technology has been used to enhance skin permeation of gold nanoparticles [17], drugs of different molecular weights [18], low molecular-weight heparin [19], gene vectors [20], vaccines [21], therapeutic antibodies [22] and several nanocarriers [23]. MNs arrays consist of solid or hollow needles that are attached to patch-like supports. The length of the needles ranges between $70 \mu \mathrm{m}$ and $1000 \mu \mathrm{m}$ [24]. When pressed into the skin, the MNs disrupt SC forming microconduits or micropores. Subsequently, these micropores allow percutaneous delivering of compounds that are otherwise not capable to cross the skin such as large compounds and hydrophilic substances into the systemic circulation $[\mathbf{2 5}, \mathbf{2 6}]$. Upon MNs removal, the natural elasticity of skin tissue causes the formed micropores to contract in a relatively short time [27]. Mainly,
MNs-mediated transdermal and dermal drug delivery could be applied on the skin using different techniques: poke with patch, coat and poke, dissolving MNs and hollow MNs [28].

Hence, the aim of this study was to examine the possibility of transdermal delivery of LAM using biodegradable polymeric nanoparticles through microneedle transport.

\section{Materials and methods}

LAM was kindly supplied by EVA Pharm pharmaceutical Co., Cairo, Egypt, PLGA (LA:GA=75:25) (Purasorb PDLGA ${ }^{\oplus} 75 / 25$, molecular weight of 10,000 ) was obtained from Purac Biomaterials, Holland, Bovine serum albumin (BSA) was purchased from MP Biomedical LLC, France, Dichloromethan was obtained from ADWIC, Egypt. Microneedle arrays made of stainless steel 56 microneedles per $1 \mathrm{~cm}^{2}, 750 \mu \mathrm{m}$ length was provided by Prof. Mark R Prausnitz at Georgia Institute of Technology, Atlanta, GA, USA. All other chemicals were of analytical grade.

\section{Preparation of the polymeric nanoparticles}

PLGA NPs were prepared using the optimized conditions of the method reported by Wang et al [29]. The PLGA NPs were prepared using a w/o/w double emulsion-solvent evaporation method. Briefly, $0.3 \mathrm{ml}$ of internal aqueous phase $\left(w_{1}\right)$ was emulsified in $2 \mathrm{~mL}$ of PLGA dichloromethane solution [oil phase (o)] using an ultrasonic homogenizer (Ultrasonic homogenizer, 4710 Series, Cole-Parmer Instrument Co., Chicago, USA) for 60 seconds in an ice bath to form the primary emulsion $\left(w_{1} / 0\right)$. This primary emulsion was rapidly added into $4 \mathrm{ml}$ of $3 \%(\mathrm{w} / \mathrm{v})$ BSA aqueous solution [external aqueous phase $\left.\left(w_{2}\right)\right]$ and emulsified again for the same time period to form a double emulsion $\left(w_{1} / o / w_{2}\right)$.

Then, the resultant double emulsion was poured into 50 $\mathrm{mL}$ of deionized water and magnetically stirred (Magnetic stirrers, Thermolyne Corporation, Dubuque lowa, USA) for one hour at room temperature to allow evaporation of the organic solvent. The obtained NPs were collected by centrifugation at $10000 \mathrm{r} / \mathrm{min}$ for one hour (Benchtop Centrifuge, Sigma Laborzentrifugen, Germany), washed with deionized water, and freeze dried at $-80^{\circ} \mathrm{C}$ under vacuum (Freeze dryer, SIM FD8-8T, SIM international, USA). The final lyophilized product of NPs was collected and stored at $4^{\circ} \mathrm{C}$ for further evaluation.

Plain NPs $\left(\mathrm{NP}_{\mathrm{p}}\right)$ were prepared using pure deionized water as internal aqueous phase $\left(w_{1}\right)$. Before preparation of polymeric LAM-loaded NPs, the possibility of interaction between PLGA and LAM was examined and ruled out using FT-IR technique (data were not included). Two concentrations of LAM solution (10 and $20 \mathrm{mg} / \mathrm{ml}$ ) were used instead of the deionized water as internal aqueous phase for preparation of $\mathrm{NP}_{10}$ and $\mathrm{NP}_{20}$ respectively.

\section{Physicochemical characterization \\ Determination of particle size, polydispersity index and zeta potential}

Nanoparticle size (PZ), polydispersity index (PDI) and zeta potential (ZP) were measured prior to lyophilization. For 
determination of ZP, the measurement was performed using deionized water-diluted aqueous dispersions of the prepared $\mathrm{NPs}$ at $25^{\circ} \mathrm{C}$ (Zetasizer Nanoseries, Malvern Instruments Limited, UK). The experiments were repeated three times and the results were calculated as mean \pm SD.

\section{Morphological characteristics}

The morphological characteristics of the NPs were observed by transmission electron microscopy (TEM). For TEM, a droplet of NPs aqueous dispersion was placed on carbon coated copper grid and air dried. Then, the dried samples were observed using TEM (JEOL JEM-2100, JEOL Ltd, Tokyo, Japan).

\section{Percent yield, drug loading capacity and entrapment efficiency}

Drug entrapment efficiency was determined according to the method reported by Vyas et al [30]. The determination of the drug loading capacity was calculated from the unbound drug (free LAM) which remained dissolved in the dispersion medium after centrifugation. The amount of free LAM was measured in the clear supernatant at $271 \mathrm{~nm}$ spectrophotometrically (Spectro UV-VIS double beam, Labomed Inc., USA) using the supernatant of the $\mathrm{NP}_{\mathrm{p}}$ as blank. The drug loading capacity (\%LC), entrapment efficiency (\%EE) and percent yield (\%Yield) of the drug-loaded nanoparticles were calculated according to the following equations:

$$
\begin{aligned}
\% L C & =\frac{\text { Total drug }- \text { Free drug }}{\text { Wt of lyophilized nanoparticles }} \times 100 \\
\% E E & =\frac{\text { Total drug }- \text { Free drug }}{\text { Total drug amount }} \times 100 \\
\% \text { Yield } & =\frac{\text { Wt of lyophilized nanoparticles obtained }}{\text { Wt of PLGA and LAM used in preparation }} \text { X100 }
\end{aligned}
$$

In vitro release of LAM from LAM-loaded nanoparticles Release of LAM from the drug loaded NPs $\left(\mathrm{NP}_{10}\right.$ and $\left.\mathrm{NP}_{20}\right)$ and LAM solution was studied using modified vertical Franz diffusion cell [31]. Each receptor half-cell was filled with 50 $\mathrm{ml}$ of phosphate buffer $\mathrm{pH} 7.4\left(\mathrm{~PB}_{7.4}\right)$ and stirred at $100 \mathrm{rpm}$. The temperature of the receptor media was maintained at $37^{\circ} \mathrm{C} \pm 0.2^{\circ} \mathrm{C}$ throughout the experiment. Donor and receptor compartments were separated by semipermeable cellulose membrane (MW cut off of 12,000-14,000) that was equilibrated with $\mathrm{PB}_{7.4}$ prior to the experiment. Fifty milligrams of the lyophilized NPs were suspended in $2 \mathrm{ml}$ of $\mathrm{PB}_{7.4}$ and poured to the donor half-cell. Samples of $2 \mathrm{ml}$ were withdrawn at predetermined time intervals, replaced with an equal volume of fresh $\mathrm{PB}_{7.4}$ and analyzed spectrophotometrically at $271 \mathrm{~nm}$. Three replicates of each experiment were performed and the average percent of LAM released was calculated.

\section{Physical stability of LAM-loaded $\mathrm{NP}_{20}$ Measurement of PZ, PDI and ZP}

The physical stability of LAM-loaded $\mathrm{NP}_{20}$ aqueous disper- sions was evaluated as reported by Cavalli et al [32]. Aqueous dispersion of $\mathrm{NP}_{20}$ was prepared and maintained at $4^{\circ} \mathrm{C}$ in a refrigerator with no agitation or stirring. Particle size, PDI and ZP values were determined at zero time (at production day), after 24, 48 h, 1, 2, 3, 4 weeks, 2, 3, 4, 5 and 6 months.

\section{Measurement of $\mathrm{pH}$}

LAM-loaded $\mathrm{NP}_{20}$ aqueous dispersion was stored at $4^{\circ} \mathrm{C}$ in the refrigerator with no agitation or stirring over six weeks. Degradation and production of acidic by-products were assessed by monitoring $\mathrm{pH}$ lowering using $\mathrm{pH}$ meter (HANNA instruments, Romania) [6].

Permeation of the polymeric LAM-loaded $\mathrm{NP}_{20}$ across excised rabbit skin

\section{Skin preparation}

Albino male rabbits $(2-2.5 \mathrm{~kg})$ were obtained from the Pharmacology Department's Animal House. This study was approved by the Scientific Research Ethical Committee at Faculty of Pharmacy, Mansoura University and all the procedures were performed under the terms and conditions of such committee. Hair was removed from the dorsal skin with the aid of an electric shaver. During shaving, care was taken to avoid damage of the skin surface. After that, rabbits were sacrificed and the dorsal skin was separated. Then, the excised skin was treated using the method reported by Larrucea et al [33]. The adipose tissue layer of the skin was removed by rubbing with a cotton swab. Prior to the permeation experiment, the fresh excised skin was maintained in $\mathrm{PB}_{74}$ containing $0.02 \%$ sodium azide as preservative in a refrigerator at $4^{\circ} \mathrm{C}$ overnight. Just before conducting the experiment, the integrity of the skin was inspected visually and damaged parts were precluded.

\section{MNs application}

Simple and easily applied MNs-applicator was designed as mentioned by Haq et al [34]. An inverted plastic syringe with the plunger surface heated and smoothed to remove any protrusions. Acrylate adhesive was used to fix the MNs array to the top of the plunger. MNs were used in a "poke and patch" method. For MNs insertion, the optimized conditions mentioned by Gomaa et al., were used [6].

\section{Permeation experiment}

The experiment was conducted using modified vertical Franz diffusion cells (diffusion area of $7.07 \mathrm{~cm}^{2}$ ). The plain untreated and MNs-treated skin samples were mounted on the donor half-cells, with SC side towards the donor compartment and the dermal side facing the receptor compartment. Each receptor compartment was filled with $50 \mathrm{ml}$ of $\mathrm{PB}_{7.4^{\prime}}$ maintained at $37^{\circ} \mathrm{C} \pm 0.2^{\circ} \mathrm{C}$ and agitated at $100 \mathrm{rpm}$. The skin samples were left to equilibrate for one hour after mounting and donor compartments were loaded with LAM-loaded $\mathrm{NP}_{20}$ dispersed in $\mathrm{PB}_{7.4}(100 \mathrm{mg} / 2 \mathrm{ml} /$ cell) and LAM aqueous solution containing equivalent amount of LAM. Aliquots ( $2 \mathrm{ml}$ ) 
from the receptor compartment were withdrawn over 120 $h$ and replaced with an equal volume of fresh $\mathrm{PB}_{7.4}$. LAM was assayed spectrophotometrically at $271 \mathrm{~nm}$ and data corrected for receptor phase dilutions. At each time point, the cumulative LAM amount permeated through the skin was calculated and plotted as a function of time. Steady state flux values were calculated [35].

\section{Results and discussion \\ Determination of particle size, polydispersity and zeta potential}

Table 1 shows particle size, polydispersity index and zeta potential of the prepared NPs. The mean particle sizes of the prepared NPs were found to be $152.87 \pm 1.27 \mathrm{~nm}, 196.67 \pm 1.74$ $\mathrm{nm}$ and $183.8 \pm 5.59 \mathrm{~nm}$ for $\mathrm{NP}_{\mathrm{p}^{\prime}} \mathrm{NP}_{10}$ and $\mathrm{NP}_{20}$ respectively. The particle size is often used to characterize NPs, because it enables the understanding of the dispersion and aggregation processes [36]. The mean PZ of the prepared NPs were found to be small and all were in the nanorange under the preparation conditions. Hence, the prepared NPs could be well suited for possible transdermal delivery.

Table 1. Physicochemical characteristics of the prepared nanoparticulate systems.

\begin{tabular}{l|lll}
\hline \multirow{2}{*}{ Parameter } & \multicolumn{3}{|c}{ Evaluation (mean \pm SD) } \\
\cline { 2 - 4 } & $\mathrm{NP}_{\mathbf{p}}$ & $\mathrm{NP}_{10}$ & $\mathbf{N P}_{\mathbf{2 0}}$ \\
\hline PZ $(\mathrm{nm})$ & $152.87 \pm 1.27$ & $196.67 \pm 1.74$ & $183.80 \pm 5.59$ \\
PDI & $0.124 \pm 0.03$ & $0.145 \pm 0.03$ & $0.089 \pm 0.01$ \\
ZP $(\mathrm{mV})$ & $-42.2 \pm 7.35$ & $-47.5 \pm 6.85$ & $-43.2 \pm 6.55$ \\
\% Yield & $86.75 \pm 3.78$ & $82.48 \pm 7.93$ & $81.09 \pm 3.82$ \\
\%DL & ---- & $2.31 \pm 0.23$ & $3.69 \pm 0.18$ \\
\% EE & ----- & $26.31 \pm 2.80$ & $23.01 \pm 4.75$ \\
\hline
\end{tabular}

Particle size (PZ), Polydispersity index (PDI), Zeta potential (ZP), Percent yield (\% Yield), Percent drug loading (\% DL), Percent entrapment efficiency (\% EE)

The mean PDI values of the prepared NPs varied in the range of 0.089 to 0.145 . It is well known that PDI is an indicator of particle size distribution [37]. The small values of PDI indicated that the prepared NPs had uniform nanosize and homogeneous distribution. Also, it is known that the NPs size detected by the particle size analyzer is a mean value ( $z$-average) and the PDI shows the particle size distribution. Since the PZ could influence the penetration of the NPs, the PDI would also affect the penetration. Hence, reducing the PDI would decrease the variance of the transdermal permeation [23].

Zeta potentials of $\mathrm{NP}_{\mathrm{p}^{\prime}} \mathrm{NP}_{10}$ and $\mathrm{NP}_{20}$ exhibited negative values ranging from $-42.2 \mathrm{mV}$ to $-47.5 \mathrm{mV}$. ZP measurement is an important surface characterization technique which provides information concerning the surface charge of NPs. At the same time, the magnitude of ZP provides an indication of the potential stability of a colloidal system [38]. Furthermore,
ZP has a considerable influence on the interaction of NPs with charged drugs and the bioadhesion of drug delivery systems onto the biological surfaces [39]. The relationship between the particle stability and ZP is an empirical one [40]. The presence of negative charge on the surface of the prepared NPs may be due to ionization of the carboxylic end groups of PLA and PGA segments. This finding was in consistent with Ma et al., [41] and Gadad et al [42]. Moreover, the surface charge on the polymeric NPs also may influence their permeation through the skin. A comparative study using positive, negative, and neutral nanoparticles revealed that only the negatively charged NPs were able to penetrate the SC and permeate deeper to the viable epidermis. It was attributed to the charge repulsion between the negatively charged lipids of SC and the negatively charged carboxylate groups on the surface of NPs. This repulsion could result in pushing the NPs to deeper skin layers [43].

\section{Morphological characteristics}

TEM micrographs of $\mathrm{NP}_{\mathrm{p}}(\mathrm{A}), \mathrm{NP}_{10}(\mathrm{~B})$ and $\mathrm{NP}_{20}(\mathrm{C})$ nanoparticles are shown in Figure 1. It was found that the prepared NPs were spherical in shape with smooth surface and thick shell around each NP. This shell confirmed the existence of BSA layers around the particles. It is known that isometric particles with obtuse angles and edges cause less irritation than particles with sharp angles and edges. As a consequence, the obtained smoothness of the prepared NPs is not expected to cause any irritation to skin when used for transdermal delivery of LAM. Our finding was in agreement with Malhotra and Majumdar [44].

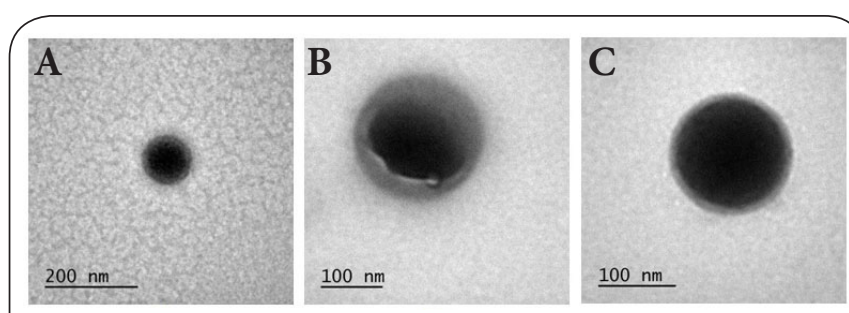

Figure 1. TEM micrograph images of plain nanoparticles (A), LAM-loaded nanoparticles $\mathrm{NP}_{10}(\mathbf{B})$ and $\mathrm{NP}_{20}(\mathbf{C})$.

\section{Percent yield, drug loading capacity and entrapment} efficiency

Table 1 shows the percent yield of $\mathrm{NP}_{\mathrm{p}^{\prime}} \mathrm{NP}_{10}$ and $\mathrm{NP}_{20^{\prime}}$ drug loading percent and entrapment efficiency of $\mathrm{NP}_{10}$ and $\mathrm{NP}_{20}$. It was found that \%Yield were $86.75 \%, 82.48 \%, 81.09 \%$ for $\mathrm{NP}_{\mathrm{p}^{\prime}} \mathrm{NP}_{10}$ and $\mathrm{NP}_{20}$ respectively. Plain NPs were prepared in the first to assess the PZ, PDI, ZP and \%Yield under the optimized conditions. After that, LAM-loaded NPs were prepared. The percentages of LAM loading were $2.31 \%$ and $3.69 \%$ for LAM-loaded $\mathrm{NP}_{10}$ and $\mathrm{NP}_{20}$ respectively. The entrapment efficiencies of LAM-loaded $\mathrm{NP}_{10}$ and $\mathrm{NP}_{20}$ were $26.31 \%$ and $23.01 \%$ respectively. It was observed that the entrapment efficiencies were relatively small which could be attributed 
to the hydrophilic nature, aqueous solubility of LAM and the hydrophobicity of the polymer. Similar finding was found by Díez and Tros de llarduya [45].

In vitro release of LAM from LAM-loaded nanoparticles Release experiment was carried out using modified vertical Franz diffusion cell instead of USP dissolution test apparatus methods. Dissolution test apparatus are generally used to evaluate drug release profiles of conventional and novel drug delivery systems of macro size. In the case of nanoparticulate systems, these apparatus are not usable due to difficulty to achieve sink conditions with NPs having a very high surface area in the existing USP methods. Furthermore, separation of the dissolved drug from undissolved NPs while sampling is difficult and non-practical [46].

The release profiles of LAM solution and drug-loaded NPs were shown in Figure 2. Lamivudine was totally released from LAM solution within 4 hours. While in case of NPs, release percentages from LAM-loaded NPs within the first two hour (also called burst release) were $19.82 \%$ and $31.83 \%$ LAM form $\mathrm{NP}_{10}$ and $\mathrm{NP}_{20}$ respectively. After the burst, an additional percent of the drug was released slowly within $120 \mathrm{~h}$ under the conditions used (Figure 2). Hence, a biphasic pattern of LAM release from the NPs was observed. Initially a faster release profile and thereafter sustained release for $120 \mathrm{~h}$. It could be suggested that a part of LAM is located at the particles surface and this part was expected to be responsible for the initial burst effect. In the same time, there is another part of LAM responsible for the subsequent slow release which expected to be the entrapped part within the particles. For transdermal

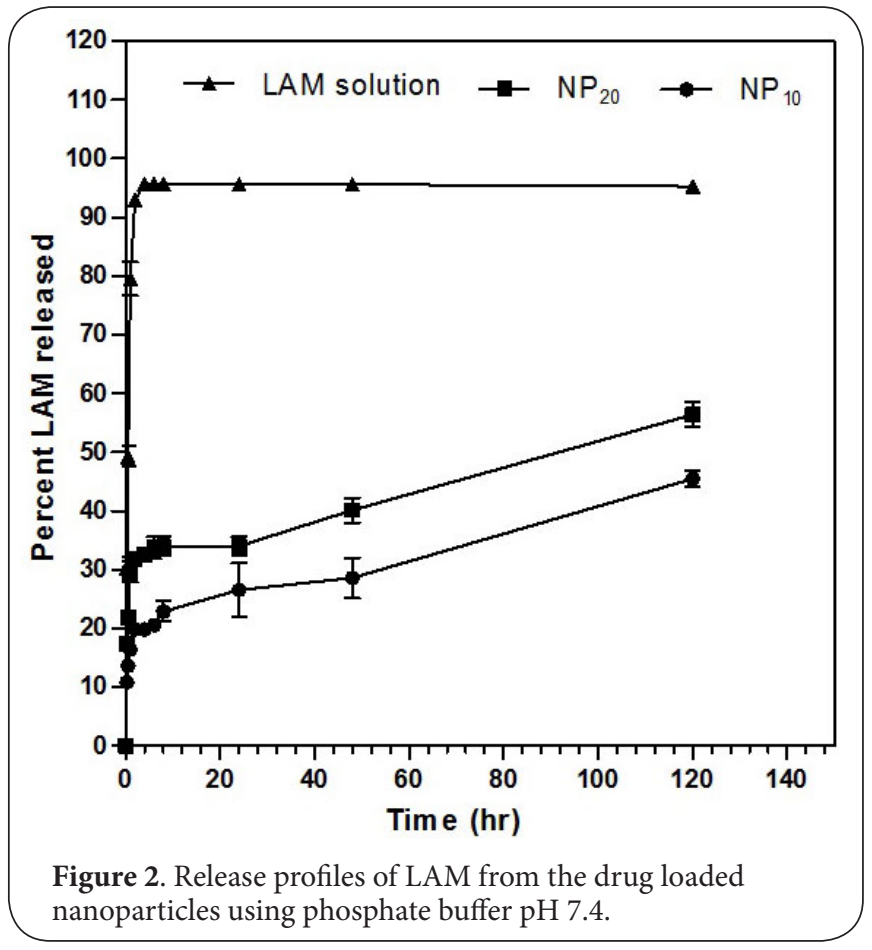

application, both features are of interest. The burst release can be useful to improve the initial penetration of the drug. While, the sustained release becomes important to supply the skin with the drug over a prolonged period of time [47]. The effect of LAM loading within the NPs appeared in the sustained release of $\mathrm{LAM}$ from both $\mathrm{NP}_{10}$ and $\mathrm{NP}_{20}$ when compared to the release from LAM solution. At all-time intervals, the percent LAM released from $\mathrm{NP}_{20}$ was higher than that released from $\mathrm{NP}_{10}$. This could be attributed to the higher $\% L C$ of $\mathrm{NP}_{20}$ than that of $\mathrm{NP}_{10}$. Hence, LAM-loaded $\mathrm{NP}_{20}$ was selected for further investigation including physical stability and permeation.

\section{Physical stability of nanoparticle suspension Measurement of PZ, PDI and ZP}

Table 2 shows particle size, polydispersity index and zeta potential of LAM-loaded $\mathrm{NP}_{20}$ suspension stored at $4^{\circ} \mathrm{C}$. The results showed that no significant variation of $\mathrm{PZ}$ could be detected and PDI did not exceed 0.186 during the storage period. This indicates that $\mathrm{NP}_{20}$ remain stable in uniform nanosize range and homogenous distribution when stored at $4^{\circ} \mathrm{C}$ for six months. To fully characterize the charge conditions of $\mathrm{NP}_{20^{\prime}}$ ZP measurements must be performed in the original dispersion medium instead of buffers or physiological salt solution.

The measurement of ZP is a measure of the diffuse layer thickness. The higher the measured ZP, the thicker the diffuse layer and the more stable is the suspension. It was found that $\mathrm{ZP}$ of $\mathrm{NP}_{20}$ were in the range of $-18.27 \mathrm{mV}$ to $-44.57 \mathrm{mV}$ during the storage period. BSA may act as a colloidal protectant via steric hindrance, preventing the small NPs from coagulating. For low-molecular weight surfactants and pure electric stabilization, absolute ZP values above $30 \mathrm{mV}$ provide good and these above $60 \mathrm{mV}$ provide excellent stability. On the other hand, for higher or large molecular weight stabilizers

Table 2. Particle size, polydispersity index and zeta potential of LAM-loaded nanoparticles in $\mathrm{NP}_{20}$ suspension stored at $4^{\circ} \mathrm{C}$

\begin{tabular}{l|lll}
\hline Storage time & \multicolumn{3}{|c}{ Evaluation $($ mean \pm SD) } \\
\cline { 2 - 4 } & PZ $(\mathbf{n m})$ & PDI & ZP $(\mathbf{m V})$ \\
\hline Zero time & $183.8 \pm 4.57$ & $0.089 \pm 0.014$ & $-37.4 \pm 1.01$ \\
$24 \mathrm{hr}$ & $190.4 \pm 3.34$ & $0.123 \pm 0.019$ & $-32.0 \pm 0.67$ \\
$48 \mathrm{hr}$ & $195.3 \pm 1.51$ & $0.126 \pm 0.024$ & $-27.7 \pm 1.86$ \\
1 week & $218.6 \pm 1.01$ & $0.186 \pm 0.015$ & $-19.40 \pm 1.12$ \\
2 weeks & $179.9 \pm 4.30$ & $0.094 \pm 0.010$ & $-23.93 \pm 0.83$ \\
3 weeks & $184.8 \pm 8.09$ & $0.112 \pm 0.009$ & $-18.27 \pm 1.11$ \\
4 weeks & $176.5 \pm 3.29$ & $0.0903 \pm 0.027$ & $-29.33 \pm 1.97$ \\
2 months & $167.6 \pm 8.49$ & $0.090 \pm 0.020$ & $-35.33 \pm 0.67$ \\
3 months & $166.3 \pm 4.61$ & $0.1096 \pm 0.026$ & $-36.63 \pm 1.12$ \\
4 months & $166.4 \pm 4.27$ & $0.101 \pm 0.015$ & $-39.70 \pm 2.26$ \\
5 months & $179.6 \pm 3.66$ & $0.134 \pm 0.006$ & $-44.57 \pm 1.36$ \\
6 months & $182.3 \pm 2.91$ & $0.167 \pm 0.012$ & $-29.7 \pm 0.93$ \\
\hline
\end{tabular}

Particle size (PZ), Polydispersity index (PDI), Zeta potential (ZP) 
Ramadan et al. Journal of Pharmaceutical Technology \& Drug Research 2016,

http://www.hoajonline.com/journals/pdf/2050-120X-5-1.pdf

which act mainly by steric stabilization, ZP values of only 20 $\mathrm{mV}$ or much lower can provide sufficient stabilization. This is due to that the adsorbed layers of large-molecular weight stabilizer shift the plane of shear to a farer distance from the particle surface which may lead to a reduction of the measured ZP [48]. Hence, the obtained results indicated enhanced and better stability of the prepared polymeric LAM-loaded $\mathrm{NP}_{20}$ which in turn enable their transdermal application for prolonged period of time.

\section{Measurement of $\mathrm{pH}$}

It was found that the value of $\mathrm{pH}$ of $\mathrm{NP}_{20}$ suspension at production day was $6.28 \pm 0.044$. This value didn't change significantly over a period of two weeks. At the third week, an increase of $\mathrm{pH}$ value was observed and continued to reach 7.36 at the sixth week. For explanation of the stability and degradation characteristics of PLGA NPs, the results of $\mathrm{pH}$ evolution and lactic acid production as a function of time could be studied [49]. Furthermore, measurement of pH up to the first week could give an idea about the possibility of skin irritation upon transdermal application of the NPs. The observed increase of $\mathrm{pH}$ could be attributed to the effect of albumin. BSA possesses functional groups that are charged according to its isoelectric point and according to the $\mathrm{pH}$ of the NPs suspension. As the isoelectric point of BSA is 4.8 , the $\mathrm{BSA}$ would be predominantly negatively charged at the $\mathrm{pH}$ of the dispersion medium [50]. It was reported that the addition of albumin solution raised the $\mathrm{pH}$ of the NPs suspension to a point close to neutrality [51]. The good stability could be related to that when the NPs were incubated at $4^{\circ} \mathrm{C}$ under no agitation, both the collisions and the degradation of NPs might be slowed down which in turn resulted in equal and stable $\mathrm{NP}_{20}$ composition during the storage period [52]. The values of $\mathrm{pH}$ also preclude the possibility of skin irritation upon transdermal application.

\section{Permeation of LAM-loaded $\mathrm{NP}_{20}$ across the excised rabbit skin}

The experiment was performed on the fresh unfrozen excised rabbit skin that was stored in the refrigerator overnight. It was reported that skin freshness is the best because freezing of skin changes permeability characteristics while skin storage in the refrigerator keeps the metabolic activity [53]. Cumulative amount per unit area $\left(\mu \mathrm{g} / \mathrm{cm}^{2}\right)$ versus time graphs of passive and MNs-mediated permeation of $\mathrm{NP}_{20}$ and LAM solution were plotted and shown in Figure 3.

It was found that the cumulative amounts permeated of LAM from LAM solution across plain and MNs-treated skin were $508.45 \pm 32.6 \mu \mathrm{g} . \mathrm{cm}^{-2}$ and $491.25 \pm 22.25 \mu \mathrm{g} . \mathrm{cm}^{-2}$ respectively without statistical significant difference (student $t$-test, $P>0.05$ ). The value of $J_{s s}$ across plain skin was lower $\left(16.6 \pm 3.1 \mu \mathrm{g} . \mathrm{cm}^{-2}\right.$ $\left.\mathrm{hr}^{-1}\right)$ than that across MNs-treated skin $\left(29.36 \pm 12.3 \mu \mathrm{g} \cdot \mathrm{cm}^{-2} \mathrm{hr}^{-1}\right)$ which could be attributed to the penetration enhancing effect of the MNs. For $\mathrm{NP}_{20^{\prime}}$ LAM permeated amount was enough to

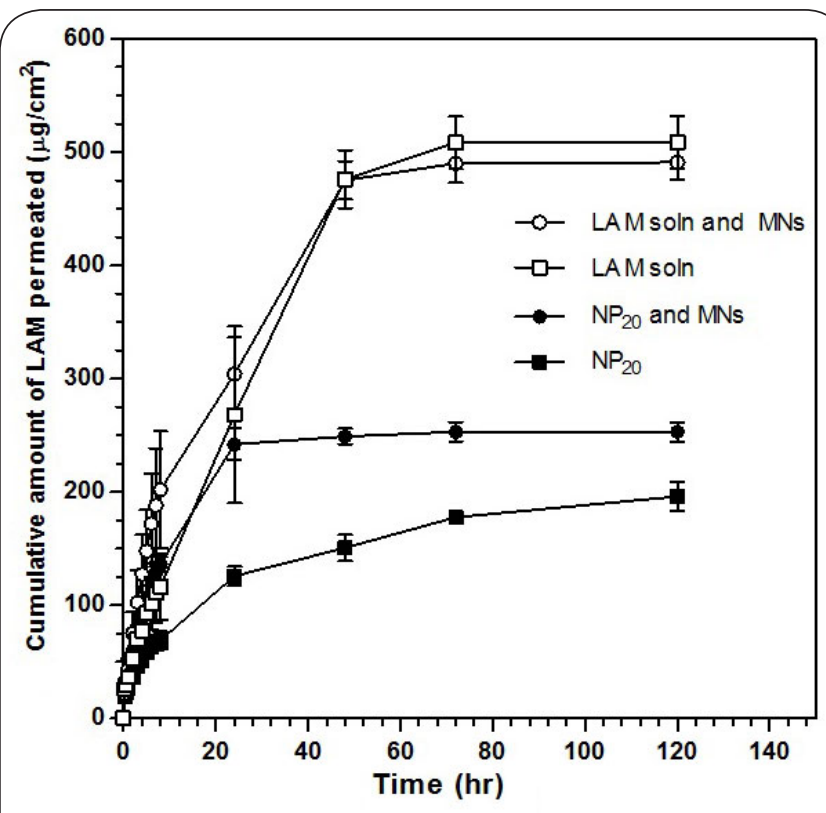

Figure 3. Cumulative amounts permeated of LAM from LAM solution (LAM soln) and drug-loaded $\mathrm{NP}_{20}$ across plain and MNs-treated rabbit skin.

be measured spectophotometrically which in turn indicated the possibility of transdermal delivery of considerable amounts of the drug using the prepared nanoparticles. The penetration enhancing effect of MNs-treatment appeared clear for $\mathrm{NP}_{20}$ in excess of the LAM solution. All over the experiment time, it was observed that the cumulative amounts permeated of LAM from $\mathrm{NP}_{20}$ across plain rabbit skin were significantly lower than the corresponding ones of $\mathrm{NP}_{20}$ across the MNs-treated skin (one-way ANOVA, $P<0.005$ ). Also, it was found that the MNs-treatment of the skin resulted in more than two folds increase in the value $J_{s s}$. The steady state flux of LAM-loaded $\mathrm{NP}_{20}$ across the $\mathrm{MNs}$-treated skin was significantly greater $\left(15.77 \pm 1.5 \mu \mathrm{g} \cdot \mathrm{cm}^{-2} \cdot \mathrm{hr}^{-1}\right)$ than $J_{\text {ss }}$ across plain skin $(7.49 \pm 1.46$ $\mu \mathrm{g} . \mathrm{cm}^{-2} \cdot \mathrm{hr}^{-1}$ ) (one-way ANOVA, $P<0.005$ ).

A part of LAM may locate at the surface of particles and another part entrapped within the particles. The surface adsorbed part was expected to be responsible for the cumulative amounts permeated up to $24 \mathrm{hr}$ and it was comparable to the corresponding amount of LAM solution. While, the entrapped LAM part within the NPs was responsible for the subsequent amounts permeated which extends for longer time up to $120 \mathrm{hr}$. On the other hand, the permeation of LAM solution across plain or MNs-treated skin lasted shorter. It could be correlated to that LAM, which was totally present dissolved in the molecular state, diffused spontaneously from the aqueous media of the solution across the skin to the receptor media. The obtained results suggested that $\mathrm{NP}_{20}$ could serve as a potential NDDS of LAM for prolonged and sustained transdermal delivery. Furthermore, this transdermal delivery could be significantly enhanced by the MNs-treatment. 
The NPs can passively permeate into the skin by the follicular pathway mainly because NPs could not penetrate the SC barrier deeper without MNs-treatment. In the case of MNstreated skin, MNs size was in the degree of micrometer and could create much higher density channels than the hair follicles. The MNs-created micropores provide additional pathways after the SC barrier was broken and more NPs are able to be delivered deeper into the skin. Also, MNs-created microconduits in the epidermis could serve as reservoirs for NPs to keep retention and progressively diffuse in this skin layer. Moreover, the lipophilicity of PLGA could permit further gradual accumulation of NPs in the skin layers. So that, the MNs-mediated transport of $\mathrm{NP}_{20}$ may be via follicular pathway, MNs-created microconduits and accumulated NPs. Based on our findings, MNs appear to be more effective vehicles than the hair follicles to assist the permeation of NPs into the skin [23]. Similar findings about the penetration enhancing effect of MNs-treatment were found in the literatures $[6,23,54]$.

\section{Conclusion}

Transdermal delivery of LAM could be achieved using a NDDS based on polymeric LAM-loaded nanoparticulate system that provide prolonged transdermal delivery to overcome some problems associated with short LAM half-life. MNs-treatment could enhance transdermal delivery of LAM nanoparticles by providing new pathways for drug transport.

\section{List of abbreviations}

AIDS: Acquired immunodeficiency syndrome BSA: Bovine serum albumin

FT-IR: Fourier transforms infrared spectroscopy

LAM: Lamivudine

MNs: Microneedles

NP: Nanoparticle

NPs: Nanoparticles

NDDS: Novel drug delivery system

PZ: Particle size

$\%$ Yield: Percent yield

$\mathrm{PB}_{74}$ : Phosphate buffer $\mathrm{pH} 7.4$

PDI: Polydispersity index

PLGA: Polylactic-co-glycolic acid

$J_{s s}$ : Steady state flux values

SC: Stratum corneum

TEM: Transmission electron microscopy

ZP: Zeta potential

\section{Competing interests}

The authors declare that they have no competing interests.

Authors' contributions

\begin{tabular}{|l|c|c|c|c|}
\hline Authors' contributions & ER & THB & GMA & NMS \\
\hline Research concept and design & $\checkmark$ & $\checkmark$ & -- & -- \\
\hline Collection and/or assembly of data & -- & -- & -- & $\checkmark$ \\
\hline Data analysis and interpretation & -- & -- & -- & $\checkmark$ \\
\hline Writing the article & -- & -- & -- & $\checkmark$ \\
\hline Critical revision of the article & -- & $\checkmark$ & $\checkmark$ & -- \\
\hline Final approval of article & -- & $\checkmark$ & -- & -- \\
\hline Statistical analysis & -- & -- & -- & $\checkmark$ \\
\hline
\end{tabular}

\section{Acknowledgement}

The authors thank EVA Pharm pharmaceutical Co. (Cairo, Egypt) for providing lamivudine, Purac Biomaterials (Holland) for providing PLGA and Prof. Mark R Prausnitz, (School of Chemical and Biomolecular Engineering, Georgia Institute of Technology, Atlanta, GA, USA) for supplying with microneedle arrays.

Publication history

Editor: George Perry, University of Texas at San Antonio, USA.

Received: 16-Jan-2016 Final Revised: 03-Mar-2016

Accepted: 18-Mar-2016 Published: 30-Mar-2016

\section{References}

1. Dutta T and Jain NK. Targeting potential and anti-HIV activity of lamivudine loaded mannosylated poly (propyleneimine) dendrimer. Biochim Biophys Acta. 2007; 1770:681-6. | Article | PubMed

2. Strauch $S$, Jantratid $E$, Dressman JB, Junginger $H E$, Kopp $S$, Midha KK, Shah VP, Stavchansky S and Barends DM. Biowaiver monographs for immediate release solid oral dosage forms: lamivudine. J Pharm Sci. 2011; 100:2054-63. | Article | PubMed

3. Jain S, Tiwary AK, Sapra B and Jain NK. Formulation and evaluation of ethosomes for transdermal delivery of lamivudine. AAPS PharmSciTech. 2007; 8:E111. | Article | PubMed Abstract | PubMed FullText

4. Pai R and Devi KV. Lamivudine liposomes for transdermal deliveryFormulation, characterization, stability and in vitro evaluation. Int J Pharm Sci Nanotechnol. 2009; 1:317-326. I Pdf

5. Mbah C.J, Uzor R.F and Attama A.A. Transdermal delivery of lamivudine: Effect of vehicles on permeation through rat skin. Int I Nov Drug Deliv Technol. 2011; 1:185-189.

6. Gomaa YA, El-Khordagui LK, Garland MJ, Donnelly RF, Mclnnes F and Meidan VM. Effect of microneedle treatment on the skin permeation of a nanoencapsulated dye. J Pharm Pharmacol. 2012; 64:1592-602. I Article | PubMed Abstract | PubMed FullText

7. Cevc $G$ and Vierl $U$. Nanotechnology and the transdermal route: A state of the art review and critical appraisal. J Control Release. 2010; 141:27799. | Article | PubMed

8. Lembo $D$ and Cavalli R. Nanoparticulate delivery systems for antiviral drugs. Antivir Chem Chemother. 2010; 21:53-70. | Article I PubMed

9. Lademann J, Richter H, Schaefer UF, Blume-Peytavi U, Teichmann A, Otberg $\mathrm{N}$ and Sterry W. Hair follicles - a long-term reservoir for drug delivery. Skin Pharmacol Physiol. 2006; 19:232-6. | Article | PubMed

10. Wu X, Price GJ and Guy RH. Disposition of nanoparticles and an associated lipophilic permeant following topical application to the skin. Mol Pharm. 2009; 6:1441-8. | Article | PubMed

11. Alvarez-Roman R, Barre G, Guy RH and Fessi H. Biodegradable polymer nanocapsules containing a sunscreen agent: preparation and photoprotection. Eur J Pharm Biopharm. 2001; 52:191-5. | Article | PubMed

12. Cui $Z$ and Mumper RJ. Chitosan-based nanoparticles for topical genetic immunization. J Control Release. 2001; 75:409-19. | Article | PubMed

13. Rancan F, Papakostas D, Hadam S, Hackbarth S, Delair T, Primard C, Verrier B, Sterry W, Blume-Peytavi U and Vogt A. Investigation of polylactic acid (PLA) nanoparticles as drug delivery systems for local dermatotherapy. Pharm Res. 2009; 26:2027-36. | Article | PubMed

14. Lademann J, Richter H, Teichmann A, Otberg N, Blume-Peytavi U, Luengo J, Weiss B, Schaefer UF, Lehr CM, Wepf R and Sterry W. Nanoparticles-an efficient carrier for drug delivery into the hair follicles. Eur J Pharm Biopharm. 2007; 66:159-64. | Article | PubMed

15. Soppimath KS, Aminabhavi TM, Kulkarni AR and Rudzinski WE. Biodegradable polymeric nanoparticles as drug delivery devices. $J$ Control Release. 2001; 70:1-20. | Article | PubMed

16. Donnelly RF, Raj Singh TR and Woolfson AD. Microneedle-based drug delivery systems: microfabrication, drug delivery, and safety. Drug Deliv. 2010; 17:187-207. | Article | PubMed Abstract | PubMed FullText

17. Kim CS, Ahn YC, Wilder-Smith P, Oh S, Chen Z and Kwon YJ. Efficient and facile delivery of gold nanoparticles in vivo using dissolvable microneedles for contrast-enhanced optical coherence tomography. Biomed Opt Express. 2010; 1:106-113. | Article | PubMed Abstract | 


\section{PubMed FullText}

18. Banks SL, Pinninti RR, Gill HS, Paudel KS, Crooks PA, Brogden NK, Prausnitz MR and Stinchcomb AL. Transdermal delivery of naltrexol and skin permeability lifetime after microneedle treatment in hairless guinea pigs. J Pharm Sci. 2010; 99:3072-80. | Article | PubMed Abstract I PubMed FullText

19. Lanke SS, Kolli CS, Strom JG and Banga AK. Enhanced transdermal delivery of low molecular weight heparin by barrier perturbation. Int J Pharm. 2009; 365:26-33. | Article | PubMed

20. Coulman SA, Barrow D, Anstey A, Gateley C, Morrissey A, Wilke N, Allender $\mathrm{C}$, Brain $\mathrm{K}$ and Birchall JC. Minimally invasive cutaneous delivery of macromolecules and plasmid DNA via microneedles. Curr Drug Deliv. 2006; 3:65-75. | Pdf | PubMed

21. Bal SM, Ding Z, Kersten GF, Jiskoot W and Bouwstra JA. Microneedlebased transcutaneous immunisation in mice with $\mathrm{N}$-trimethyl chitosan adjuvanted diphtheria toxoid formulations. Pharm Res. 2010; 27:183747. | Article | PubMed Abstract | PubMed FullText

22. Li G, Badkar A, Nema S, Kolli CS and Banga AK. In vitro transdermal delivery of therapeutic antibodies using maltose microneedles. Int $J$ Pharm. 2009; 368:109-15. | Article | PubMed

23. Zhang W, Gao J, Zhu Q, Zhang M, Ding X, Wang X, Hou X, Fan W, Ding B, Wu $X$ and Gao $S$. Penetration and distribution of PLGA nanoparticles in the human skin treated with microneedles. Int J Pharm. 2010; 402:20512. | Article | PubMed

24. Li WZ, Huo MR, Zhou JP, Zhou YQ, Hao BH, Liu T and Zhang Y. Super-short solid silicon microneedles for transdermal drug delivery applications. Int J Pharm. 2010; 389:122-9. | Article | PubMed

25. Kelchen MN, Holdren GO, Farley MJ, Zimmerman MB, Fairley JA and Brogden NK. Optimization of impedance spectroscopy techniques for measuring cutaneous micropore formation after microneedle treatment in an elderly population. Pharm Res. 2014; 31:3478-86. Article | PubMed

26. Wermeling DP, Banks SL, Hudson DA, Gill HS, Gupta J, Prausnitz MR and Stinchcomb AL. Microneedles permit transdermal delivery of a skinimpermeant medication to humans. Proc Natl Acad Sci U S A. 2008; 105:2058-63. | Article | PubMed Abstract | PubMed FullText

27. Kalluri $\mathrm{H}$ and Banga AK. Formation and closure of microchannels in skin following microporation. Pharm Res. 2011; 28:82-94. | Article | PubMed

28. Tuan-Mahmood TM, McCrudden MT, Torrisi BM, McAlister E, Garland MJ, Singh TR and Donnelly RF. Microneedles for intradermal and transdermal drug delivery. Eur J Pharm Sci. 2013; 50:623-37. | Article | PubMed Abstract | PubMed FullText

29. Wang B, Chen G, Mao Z, Zhang Y, Yu D and Gao C. Preparation and cellular uptake of PLGA particles loaded with lamivudine. Chin Sci Bull. 2012; 57:3985-3993. I Article

30. Vyas A, Saraf S and Saraf S. Encapsulation of cyclodextrin complexed simvastatin in chitosan nanocarriers: A novel technique for oral delivery. J Incl Phenom Macrocycl Chem. 2009; 66:251-259.

31. Santander-Ortega MJ, Stauner T, Loretz B, Ortega-Vinuesa JL, BastosGonzalez D, Wenz G, Schaefer UF and Lehr CM. Nanoparticles made from novel starch derivatives for transdermal drug delivery. $J$ Control Release. 2010; 141:85-92. | Article | PubMed

32. Cavalli R, Donalisio M, Civra A, Ferruti P, Ranucci E, Trotta F and Lembo D. Enhanced antiviral activity of Acyclovir loaded into beta-cyclodextrinpoly(4-acryloylmorpholine) conjugate nanoparticles. J Control Release. 2009; 137:116-22. | Article | PubMed

33. Larrucea E, Arellano A, Santoyo $S$ and Ygartua P. Interaction of tenoxicam with cyclodextrins and its influence on the in vitro percutaneous penetration of the drug. Drug Dev Ind Pharm. 2001; 27:251-60. | Article I PubMed

34. Haq MI, Smith E, John DN, Kalavala M, Edwards C, Anstey A, Morrissey A and Birchall JC. Clinical administration of microneedles: skin puncture, pain and sensation. Biomed Microdevices. 2009; 11:35-47. | Article | PubMed

35. Chen H, Chang X, Du D, Liu W, Liu J, Weng T, Yang Y, Xu H and Yang $X$. Podophyllotoxin-loaded solid lipid nanoparticles for epidermal targeting. J Control Release. 2006; 110:296-306. | Article | PubMed

36. Desai MP, Labhasetwar V, Walter E, Levy RJ and Amidon GL. The mechanism of uptake of biodegradable microparticles in Caco- 2 cells is size dependent. Pharm Res. 1997; 14:1568-73. | Article | PubMed
37. Cegnar M, Kos J and Kristl J. Cystatin incorporated in poly(lactide-coglycolide) nanoparticles: development and fundamental studies on preservation of its activity. Eur J Pharm Sci. 2004; 22:357-64. | Article | PubMed

38. Li LC and Tian Y. Zeta potential. Encycl Pharm Technol. 2007; 6:4117-28.

39. Jain $D$ and Banerjee R. Comparison of ciprofloxacin hydrochlorideloaded protein, lipid, and chitosan nanoparticles for drug delivery. $J$ Biomed Mater Res B Appl Biomater. 2008; 86:105-12. | Article | PubMed

40. Schwarz C, Mehnert W, Lucks JS and Müller RH. Solid lipid nanoparticles (SLN) for controlled drug delivery. I. Production, characterization and sterilization. J Controlled Release. 1994; 30:83-96. | Article

41. Ma Y, Zheng Y, Liu K, Tian G, Tian Y, Xu L, Yan F, Huang L and Mei L. Nanoparticles of Poly(Lactide-Co-Glycolide)-d-a-Tocopheryl Polyethylene Glycol 1000 Succinate Random Copolymer for Cancer Treatment. Nanoscale Res Lett. 2010; 5:1161-9. | Article | PubMed Abstract | PubMed FullText

42. Gadad AP, Sharath Chandra P, Dandagi PM and Mastiholimath VS. Moxifloxacin loaded polymeric nanoparticles for sustained ocular drug delivery. Int J Pharm Sci Nanotechnol. 2012; 5:1727-1734. | Pdf

43. Kohli AK and Alpar HO. Potential use of nanoparticles for transcutaneous vaccine delivery: effect of particle size and charge. Int J Pharm. 2004; 275:13-7. | Article | PubMed

44. Malhotra M and Majumdar DK. Permeation through cornea. Indian J Exp Biol. 2001; 39:11-24. I Pdf

45. Diez $\mathrm{S}$ and Tros de llarduya C. Versatility of biodegradable poly(D,Llactic-co-glycolic acid) microspheres for plasmid DNA delivery. Eur J Pharm Biopharm. 2006; 63:188-97. | Article | PubMed

46. Murthy RS. In vitro evaluation of nanoparticulate drug delivery systems. In Drug Delivery Nanoparticles Formulation and Characterization. Edited by Pathak Y, Thassu D. New York: Informa Healthcare USA; 2009; 191:156-168.

47. de Jalon EG, Blanco-Prieto MJ, Ygartua P and Santoyo S. Topical application of acyclovir-loaded microparticles: quantification of the drug in porcine skin layers. J Control Release. 2001; 75:191-7. | Article PubMed

48. Mishra PR, Al Shaal L, Muller RH and Keck CM. Production and characterization of Hesperetin nanosuspensions for dermal delivery. Int J Pharm. 2009; 371:182-9. | Article | PubMed

49. Santander-Ortega MJ, Csaba N, González L, Bastos-González D, Ortega-Vinuesa JL and Alonso MJ. Protein-loaded PLGA-PEO blend nanoparticles: encapsulation, release and degradation characteristics. Colloid Polym Sci. 2010; 288:141-150. | Article

50. Chen Y, Mohanraj VJ, Wang F and Benson HA. Designing chitosandextran sulfate nanoparticles using charge ratios. AAPS PharmSciTech. 2007; 8:E98. | Article | PubMed Abstract | PubMed FullText

51. Woitiski CB, Neufeld RJ, Ribeiro AJ and Veiga F. Colloidal carrier integrating biomaterials for oral insulin delivery: Influence of component formulation on physicochemical and biological parameters. Acta Biomater. 2009; 5:2475-84. | Article | PubMed

52. Avgoustakis K, Beletsi A, Panagi Z, Klepetsanis P, Livaniou E, Evangelatos $G$ and Ithakissios DS. Effect of copolymer composition on the physicochemical characteristics, in vitro stability, and biodistribution of PLGA-mPEG nanoparticles. Int J Pharm. 2003; 259:115-27. | Article | PubMed

53. Wester RC and Maibach HI. In vitro testing of topical pharmaceutical formulation. In Topical Drug Delivery Formulations. Edited by Osborne DW, Amann AH. New york: Marcel Dekker. 1989; 213-220.

54. Kaur M, Ita KB, Popova IE, Parikh SJ and Bair DA. Microneedle-assisted delivery of verapamil hydrochloride and amlodipine besylate. Eur J Pharm Biopharm. 2014; 86:284-91. | Article | PubMed

\section{Citation:}

Ramadan E, Borg T, Abdelghani GM and Saleh NM. Transdermal microneedle-mediated delivery of polymeric lamivudine-loaded nanoparticles. J Pharm Technol Drug Res. 2016; 5:1. http://dx.doi.org/10.7243/2050-120X-5-1 